\title{
Better Living Through Technology
}

\author{
David J. Gunkel ${ }^{1}$
}

Published online: 7 November 2015

(C) Springer Science+Business Media Dordrecht 2015

\begin{abstract}
In this brief response to Mark Coeckelbergh's contribution, I demonstrate how the author introduces an important shift in the way we approach technology. Instead of focusing on the new and often-times dramatic existential vulnerabilities supposedly introduced by technological innovation, Coeckelbergh targets the way technology already transforms our existential vulnerabilities. And I show how this shift in focus has three very important consequences: (1) a different way to ask about and investigate the question concerning technology, (2) the importance of hacking as a mode of responding to this question and (3) the significance of questioning as a philosophical project.
\end{abstract}

Keywords Technology $\cdot$ Martin Heidegger $\cdot$ Hacking $\cdot$ Philosophy $\cdot$ Artificial Intelligence

The main objective of Mark Coeckelbergh's "The Art of Living with ICTs" is to shift the focus of the question concerning technology. As Coeckelbergh explains, "technologies are not so much external objects that produce risks we then have to deal with, but rather always already transform our existential vulnerability." A good illustration of this can be seen by reconsidering the recent AI panic, fueled by the apocalyptic warnings issued by Stephen Hawking and Elon Musk, who worry that the development of intelligent machines could be the biggest existential threat to the human species. Coeckelbergh's concern, however, is not with the new existential vulnerabilities introduced by technological innovation. His question is not framed by science fiction and the assumption that technology constitutes an external,

This comment refers to the article available at doi:10.1007/s10699-015-9436-9.

A reply to this comment is available at doi:10.1007/s10699-015-9439-6.

David J. Gunkel

dgunkel@niu.edu

1 Northern Illinois University, Dekalb, IL, USA 
alien threat that will invade our lives and perhaps put an end to it. His concern is less dramatic and more nuanced: Recognizing that human existence is always in the state of being-vulnerable, how does technology, and information and communication technology (ICT) in particular, shape the way we cope with the existential vulnerabilities that define our very existence? This fundamental shift in perspective has at least three consequences.

\section{Heideggerian Framework}

Coeckelbergh's change in perspective, although not specifically identified as such, is Heideggarian. In the essay "The Question Concerning Technology," which was initially published in the mid-1950s, Heidegger distinguished between technology understood as a tool or instrument of human endeavor — what has been called, by Andrew Feenberg (1991) and others, "the instrumental definition of technology" - and an understanding of technology as essentially a mode of the revealing of being that Heidegger calls Gestell. In this way, "technology," as Heidegger (1977, p. 12) explains, "is no mere means." It is a way of structuring or "enframing" (the standard English translation of Gestell) our world. As if channeling Heidegger, Coeckelbergh writes the following: "Thus, technology is not simply a matter of 'artefacts' or 'things,' but shapes how we see reality (it shapes our world)."

This is not to say that Coeckelbergh simply reproduces Heidegger or that what Coeckelbergh writes can or should be reduced to the Heideggerian perspective. Instead I want to draw two conclusions from this remarkable convergence. On the one hand, what Coeckelbergh advances in his essay is not something that is unprecedented. The shift in perspective concerning the question concerning technology is something that already concerned Heidegger. Despite the fact that we often attribute to ICT innovations of unprecedented scale and effect, the fact of the matter is that the essence of technology has changed little and the important fundamental questions persist. These questions exceed the mere calculation of cost versus benefit and require a deeper philosophical reflection on what it means to live not only with but also through technology.

On the other hand, Coeckelbergh's analysis provides us with something that Heidegger does not. Although Heidegger famously located the "saving power" within the danger of technology - a danger that is situated in the very essence of the technological and that "does not come in the first instance from the potentially lethal machines and apparatus of technology" (Heidegger 1977, p. 28) - he does not provide much by way of normative prescriptions. In other words, Heidegger may provide an insightful diagnosis of technology, but he does not offer much by way of actual techne. Coeckelbergh, on the contrary, is concerned with developing not just the knowledge but the know-how for deciding how one lives technologically. This is, as Coeckelbergh correctly points out, both a moral and aesthetic task, and this particular art of living — the becoming "vulnerability artists," which sounds more like Kafka than Heidegger-is not something that can be theorized but must be developed in and by practice. This immediately leads us to the second point.

\section{The Ethics of Hacking}

Although technology shapes our reality or "being-in-the-world," to use Heidegger's term, this does not necessarily commit one to a technological determinist perspective. As Coeckelbergh rightly points out, we are not just the victims; we also have a hand in shaping 
the technologies that shape our world. Consequently, we are not powerless in the face of technological change. "We have," as Coeckelbergh argues, "some room to change our risks and vulnerabilities, that is, room to change our living-with-technologies." And according to Coeckelbergh this often comes down to a matter of design. "Trying to design different technologies, then, is one way of trying to find different styles of (coping with) vulnerability-technology and to achieve different forms of life." But design is not the only mode of intervention, and Coeckelbergh remains suspicious of locating everything on the design-side of the equation. Users and "the culture of use and interpretation," as Coeckelbergh describes it, also have a responsibility and a role to play. We can, individually and in collaboration with each other, always use technology differently and otherwise. We can, in particular, employ them in excess and against the intentions of their original design. As William Gibson (1993, p. 29) once described it: "The street finds its own use for thingsuses the manufacturer never imagined."

This is a crucial component of Coeckelbergh's understanding of know-how and a principal strategy for coping with technological vulnerabilities. I would only add to this a small, nominal item-we should call this hacking. In other words, successfully living with and through technology requires the practical skill and know-how of a hacker. As Andrew Ross (1991) once described it: "If there is a challenge here for cultural critics, then it might be presented as the obligation to make our knowledge about technoculture into something like the hacker's knowledge." Long before the term "hacker" became usurped by the popular press as the quintessential "bogey man" of ICT, hacking was characterized as a life-style and a strategy for dealing with the culture of technology. Consequently, the social shaping of technology and the technological shaping of the social are not just a matter of design. End users always re-engineer, repurpose, reconfigure, and remix. And it is this process of reconfiguration that is essential for successfully living with technology. Although Coeckelbergh does not say it as such, hacking has the potential to become a kind of moral thinking in action and, for this reason, we have an obligation to transform our knowledge of ICT into a hacker's know-how.

\section{Unanswered Questions}

Because the goal of the essay is to learn how to ask new and different questions, the text ends rather inconclusively. It concludes not with an answer or set of answers but with more questions. From one perspective, this can be considered bad form, insofar as it is assumed that a piece of academic writing should respond to and answer its own research question. But this is not necessarily the case, especially for philosophy. Philosophers as varied as Martin Heidegger, G. E. Moore, Daniel Dennett, and Slavoj Žižek have all, at one time or another, argued that the principal objective of philosophy is not to supply answers to difficult questions but to examine the questions themselves and our modes of inquiry. "The task of philosophy," Žižek (2006, p. 137) writes, "is not to provide answers or solutions, but to submit to critical analysis the questions themselves, to make us see how the very way we perceive a problem is an obstacle to its solution." This is precisely what Coeckelbergh sets out to do and accomplishes.

To return to the AI panic with which we began, the question "Will AI kill off the human species?" is the wrong question. It is a distraction that makes us miss the more important questions concerning the way that technological developments in AI already shape the very existence we mistakenly assume they then threaten. Coeckelbergh does not want to address 
the usual questions - those questions that proceed from the understanding of technology as a neutral tool of human activity. Instead he wants to reengineer the question concerning technology, in a way that is similar to Heidegger, in order to ask a different set of questions. These questions are not just academic but matter for how we live with technology now and in the future. As Coeckelbergh (2015) wrote in response to Hawking and Musk, "these issues are far less sexy perhaps than that of super-intelligence or the end of humankind. They are not about intelligence or about robots as such; they are about what kinds of lives and what kind of society we want to have."

\section{References}

Coeckelbergh, M. (2015). Sure, artificial intelligence may end our world, but that is not the main problem. Wired. http://www.wired.com/2014/12/armageddon-is-not-the-ai-problem/.

Feenberg, A. (1991). Critical theory of technology. Oxford: Oxford University Press.

Gibson, W. (1993). Academy leader. In M. Benedikt (Ed.), Cyberspace: First steps (pp. 27-29). Cambridge: The MIT Press.

Heidegger, M. 1977. The question concerning technology. Trans. by William Lovitt. New York: Harper \& Row.

Ross, A. (1991). Technoculture. Minneapolis: University of Minnesota Press.

Žižek, S. (2006). Philosophy, the 'unknown knowns', and the public use of reason. Topoi, 25(1-2), 137-142.

David J. Gunkel (Ph.D. DePaul University, Philosophy) is Distinguished Teaching Professor in the Department of Communication at Northern Illinois University (USA). He is the author of six books addressing the philosophical aspects of information and communication technology, including The Machine Question: Critical Perspectives on AI, Robots and Ethics (MIT Press, 2012), Of Remixology: Ethics and Aesthetics After Remix (MIT Press, 2016), Thinking Otherwise: Philosophy, Communication, Technology (Purdue University Press, 2007), and Hacking Cyberspace (Westview, 2001). More information can be obtained from http://gunkelweb.com. 